\title{
Online Video-based Supplement for Assessment of Preterm Infant Behavior (APIB) and Newborn Individualized Developmental Care and Assessment Program (NIDCAP) Education
}

Dyck Na,b,c, Tyebkhan JM"a,b,c, Nykipilo A $^{a, c}$

a Stollery Children's Hospital

bUniversity of Alberta

'Edmonton NIDCAP Training Centre Canada (ENTCC), Edmonton, Alberta, Canada

\section{Aims}

In response to repeated requests for enhanced educational materials for NIDCAP and APIB training, NIDCAP Federation International (NFI) members were asked in October 2016 to share photos and videos for the creation of a photographic library.

Video offers several advantages over verbal or written communication and education, and has been shown to improve technical and non-technical neonatal resuscitation skills. ${ }^{1}$ The presentation of large amounts of information in a limited amount of space and time, simplifying complex/abstract concepts, demonstrating how concepts/subjects in motion relate to one another, engaging audience attention and retention of information are enhanced ${ }^{2}$; all these are educational goals of NIDCAP Training.

Our experience of video-supplemented NIDCAP education concurs with these findings. Thus, we have created an online video-based tool to Supplement APIB and NIDCAP Education. Our goals were to a) create this tool, b) present this work at the 2018 NIDCAP Trainers Meeting (NTM) for feedback from the NFI membership, and c) invite collaboration from the membership to expand this preliminary work.

\section{Methods}

Parents and staff providing care to NICU Infants $(\mathrm{N}=21)$, at the Stollery Children's Hospitals, gave written consent for videotaping of caregiving interventions. A variety of caregiving procedures, (clinical examinations including the APIB, diaper changes, needle sticks, procedures, etc.) were captured on video. Videos reviewed by JMT and AN were categorized according to Synactive Subsystems, (for the NIDCAP section) ${ }^{3}$ and Systems, Packages or Summary Scales (for the APIB section). ${ }^{4}$ Many video clips raised questions related to NIDCAP observations and/or APIB examinations and scoring and were placed in a separate section, 'Platform for Debate'. Videos in the Platform for Debate section were linked to feedback forms to facilitate e-mail communication with the Edmonton NIDCAP Training Center Canada (ENTCC), so that NFI members can offer their perspectives and insights. All videos were uploaded to a password protected database and website.

\section{Results/Findings}

Video captured more detail than transcription onto NIDCAP observation sheets. Similarly, video of APIB exams led to more detailed scoring, than the scoring based on examiner's memory. The videos often provided a different view of the infant, com-

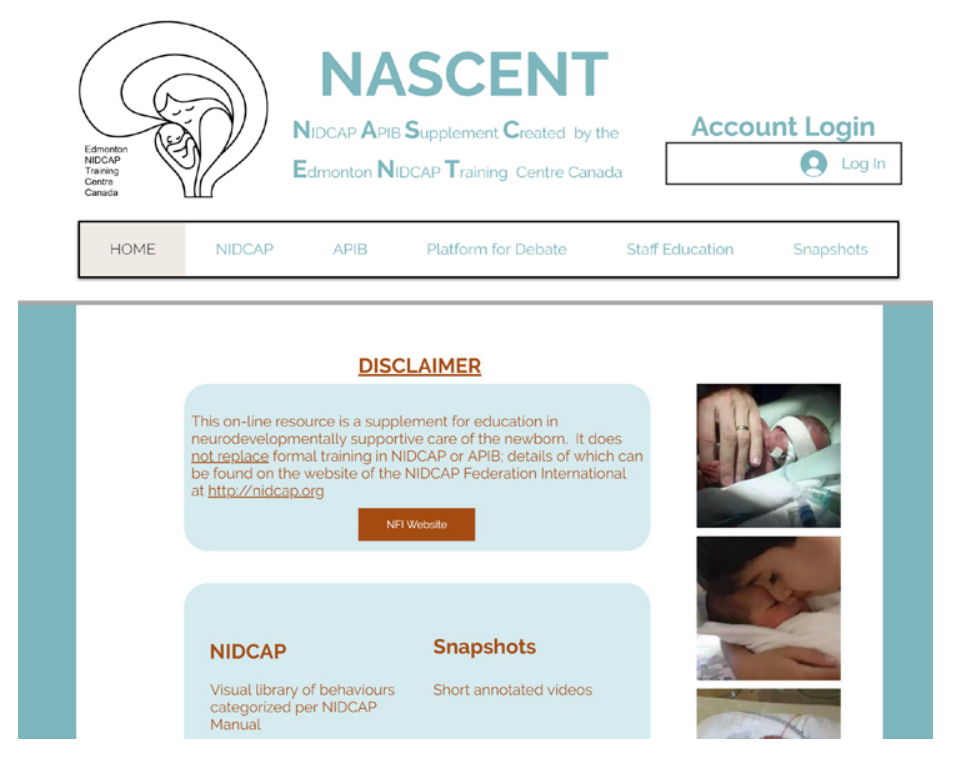

Image of the NASCENT homepage.

pared to that of the observer, thus affording a more complete record of the infant's behavioral patterns. The videos will be shown during our presentation at the Trainers Meeting. We invite discussion at the NTM regarding members' feedback about the user-friendliness and utility of this resource and the possibilities of forming a Working Group to expand this work.

\section{Conclusion and Further Plans}

We will continue to record and upload videos, and welcome others to submit videos for inclusion in this online learning resource. We anticipate this resource will be used by NIDCAP and APIB trainers and trainees as a supplement to the NFI Training Manuals. We hope the "Platform for Debate" section will serve as a forum for collaborative discussion about the complexities of neurobehavioral observation and scoring. Electronic resources support trainers and trainees to review and discuss the complexities of behavioral responses and APIB scoring online which may shorten the time required for training. Such resources also allow review of behavioral response patterns and corresponding APIB scores not observed during formal training days. We hope the online communication channel of this resource will enhance the skills of all who strive to provide NIDCAP-based, individualized neurobehavioral care for infants in their nurseries.

Addendum: In discussion with senior author Juzer Tyebkhan, the NASCENT program has been recognized as a new teaching tool under the auspices of the NFI's Program Committee. NASCENT is a promising new tool to support APIB and NIDCAP training. 
1. Skåre C, Calisch TE, Sæter E, Rajka T, Boldingh AM, Nakstad B, Niles DE, Kramer-Johansen J, Olasveengen TM. Implementation and effectiveness of a video-based debriefing programme for neonatal resuscitation. Acta Anaesthesiologica Scandinavica. 2018; 62:394-403. https://doi. org/10.1111/aas.13050.

2. Hurtubise L, Martin B, Gilliland A, Mahan J. To play or not to play: Leveraging video in medical education. Journal of Graduate Medical Education. 2013; 5(1):13-18. http://doi. org/10.4300/JGME-05-01-32.
3. Als, H. Manual for the Naturalistic Observation of Newborn Behavior. NIDCAP Federation International. 2006. Retrieved from http://nidcap.org.

4. Als H, Lester B, Tronick E, Brazelton B. Manual for the Assessment of Preterm Infants' Behavior (APIB). NIDCAP Federation International. 2006. Retrieved from http://nidcap.org. 